Indonesian Journal of Pharmaceutical Education (e-Journal) 2021; 1 (1): 30 -39
ISSN: 2775-3670 (online)
Journal Homepage: $\frac{\text { http://ejurnal.ung.ac.id/index.php/ijpe/index }}{\text { DOI: } \underline{10.22487 / . i j p e . v l i 1.9951}}$

\title{
Uji Aktivitas Antioksidan Minyak Argan (Argania spinosa L.) Dalam Bentuk Sediaan Mikroemulsi
}

\begin{tabular}{|c|c|}
\hline \multicolumn{2}{|c|}{$\begin{array}{l}\text { Nur Ain Thomas }{ }^{*} \text {, Juliyanty Akuba }{ }^{2} \text {,Moh. Adam Mustapa }{ }^{3} \text {,Adiva Sidangoli }{ }^{4} \\
\text { 1,2Jurusan Farmasi, Fakultas Olahraga dan Kesehatan, Universitas Negeri Gorontalo, Gorontalo } \\
{ }^{*} \text { E-mail: nurain.thomas@gmail.com }\end{array}$} \\
\hline $\begin{array}{l}\text { Article Info: } \\
\text { Received: } 21 \text { September } \\
2020 \\
\text { in revised form: } 13 \text { Oktober } \\
2020 \\
\text { Accepted: } 1 \text { Februari } \\
\text { Available Online: } 1 \text { Februari } \\
2021\end{array}$ & $\begin{array}{l}\text { Argan oil (Argania spinosa L.) is an oil that has benefits as a natural } \\
\text { antioxidant which is good for health. Microemulsion is a } \\
\text { thermodynamically stable delivery system; transparent; has a small } \\
\text { globule size and consists of a mixture of oil, water, surfactant and co- }\end{array}$ \\
\hline $\begin{array}{l}\text { Keywords: } \\
\text { Antioxidant } \\
\text { Microemulsion } \\
\text { Argan Oil } \\
\text { Argania spinosa L. }\end{array}$ & $\begin{array}{l}\text { substances by increasing transdermal permeability in topical drug } \\
\text { delivery. This research aimed to formulate argan (Argania spinosa L.) } \\
\text { oil into microemulsion dosage form and determine the antioxidant } \\
\text { activity using DPPH method. The study began with the optimization }\end{array}$ \\
\hline $\begin{array}{l}\text { Corresponding Author: } \\
\text { Nur Ain Thomas } \\
\text { Jurusan Farmasi } \\
\text { Fakultas Olahraga dan } \\
\text { Kesehatan } \\
\text { Universitas Negeri } \\
\text { Gorontalo } \\
\text { E-mail: } \\
\text { nurain.thomas@gmail.com }\end{array}$ & 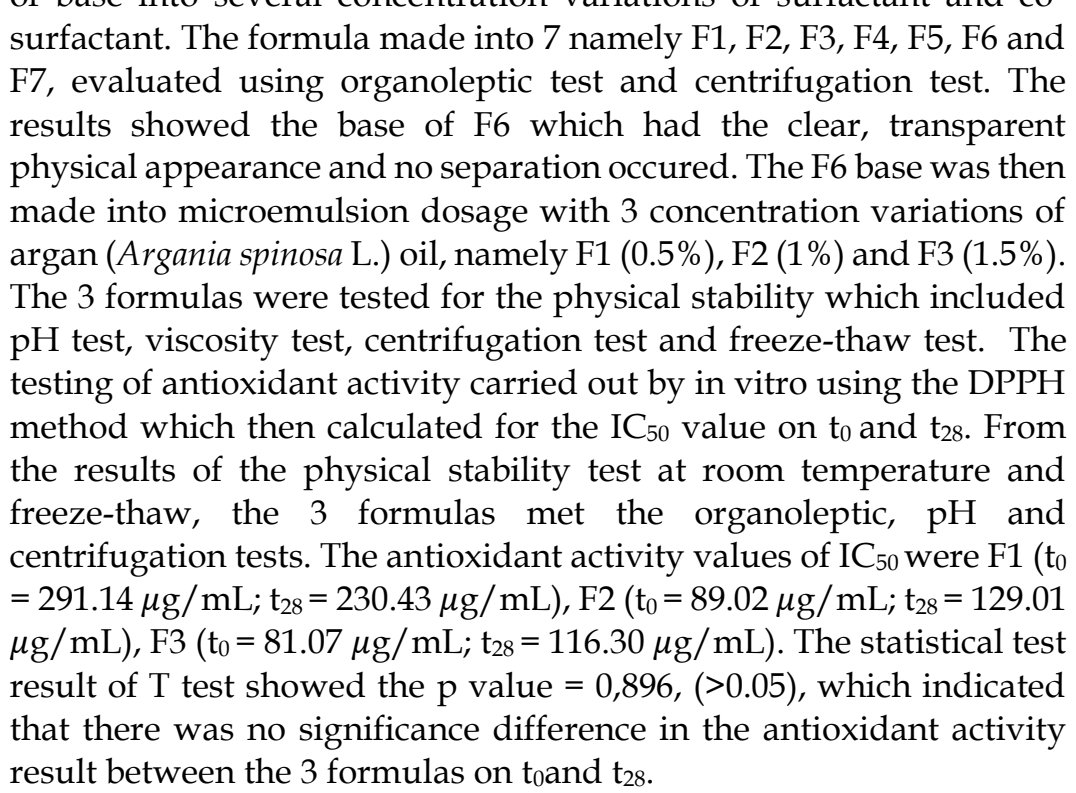 \\
\hline
\end{tabular}

C) (1) (9)
This open access article is distributed under a Creative Commons Attribution
CCC-BY-NC-SA) 4.0 International
license.

How to cite (APA $6^{\text {th }}$ Style):

Thomas.N.A.,Akuba.J.,Mustapa.M.,Sidangoli.A.(2021). Uji Aktivitas Antioksidan Minyak Argan (Argania spinosa L.) Dalam Bentuk Sediaan Mikroemulsi.Indonesian Journal of Pharmaceutical (e-Journal), 1(1), 30-39. 


\section{ABSTRAK}

Minyak Argan (Argania spinosa L.) merupakan salah satu minyak yang memiliki manfaat antioksidan alami yang baik untuk kesehatan. Mikroemulsi adalah suatu sistem penghantaran yang stabil secara termodinamika, transparan, memiliki ukuran globul yang kecil, terdiri dari campuran minyak, air, surfaktan dan ko-surfaktan yang memiliki potensi besar dalam penghantaran zat aktif secara dermal dengan meningkatkan permeabilitas transdermal dalam penghantaran obat secara topikal. Tujuan dari penelitian ini adalah untuk memformulasikan minyak argan (Argania spinosa L.) dalam bentuk sediaan mikroemulsi serta mengetahui aktivitas antioksidannya menggunakan metode DPPH. Penelitian diawali dengan optimasi basis dengan variasi konsentrasi surfaktan dan kosurfaktan. Dibuat 7 formula basis yaitu F1, F2, F3, F4, F5, F6 dan F7. Ketujuh formula dievaluasi organoleptik dan sentrifugasi. Didapatkan basis F6 yang memiliki tampilan fisik jernih, transparan dan tidak terjadi pemisahan. Basis F6 dibuat sediaan mikroemulsi dengan 3 variasi konsentrasi minyak argan (Argania spinos L.), F1 0,5\%, F2 1\% dan F3 1,5\%. Ketiga formula diuji stabilitas fisik meliputi uji pH, viskositas, sentrifugasi dan freezethaw, pengujian aktivitas antioksidan secara in vitro menggunakan metode DPPH, dihitung nilai IC50 pada $\mathrm{t}_{0}$ dan $\mathrm{t}_{28}$. Hasil uji stabilitas fisik sediaan pada suhu ruang dan freeze-thaw, ketiga formula memenuhi uji organoleptik, $\mathrm{pH}$ dan sentrifugasi. Nilai aktivitas antioksidan dengan nilai IC $\mathrm{I}_{50} \mathrm{~F} 1\left(\mathrm{t}_{0}=291.14 \mu \mathrm{g} / \mathrm{mL} ; \mathrm{t}_{28}=230.43 \mu \mathrm{g} / \mathrm{mL}\right), \mathrm{F} 2\left(\mathrm{t}_{0}=89.02\right.$ $\left.\mu \mathrm{g} / \mathrm{mL} ; \mathrm{t}_{28}=129.01 \mu \mathrm{g} / \mathrm{mL}\right), \mathrm{F} 3\left(\mathrm{t}_{0}=81.07 \mu \mathrm{g} / \mathrm{mL} ; \mathrm{t}_{28}=116.30 \mu \mathrm{g} / \mathrm{mL}\right)$. Hasil uji statistik T Test $\mathrm{p}$ value $=0,896,(>0.05)$, menunjukkan tidak ada perbedaan signifikan hasil aktivitas antioksidan ketiga formula pada $t_{0}$ dan $t_{28}$.

Kata Kunci: Antioksidan, Mikroemulsi, Minyak Argan, Argania spinosa L.

\section{Pendahuluan}

Salah satu penyebab timbulnya berbagai penyakit kronis dan degeneratif adalah radikal bebas. Radikal bebas memiliki energi yang tinggi dan bersifat sangat reaktif, yang disebabkan oleh kandungan elektron yang tidak berpasangan pada orbital terluarnya. Sehingga saat kadar radikal bebas di dalam tubuh melebihi batas normal, maka radikal bebas akan menjadi suatu senyawa yang berbahaya bagi tubuh manusia. Kulit merupakan organ yang melapisi seluruh permukaan tubuh makhluk hidup dan mempunyai fungsi untuk melindungi tubuh dari pengaruh luar. Efek oksidatif radikal bebas dapat menyebabkan peradangan dan penuaan dini, yang disebabkan lipid pada kulit yang memiliki fungsi menjaga kulit agar tetap segar berubah menjadi lipid peroksida karena bereaksi dengan radikal bebal sehingga mempercepat penuaan.

Antioksidan merupakan senyawa yang menghambat, mencegah atau menghilangkan kerusakan oksidatif pada molekul target. Antioksidan adalah lini pertahanan pertama dalam melawan kerusakan radikal bebas, dan sangat penting untuk menjaga kesehatan dan kesejahteraan yang optimal [1]. Penggunaan antioksidan alami mendapat perhatian yang sangat besar karena penggunannya yang aman dibandingkan antioksidan sintetik. Minyak argan merupakan salah satu minyak yang berasal dari Maroko yang memiliki manfaat sebagai antioksidan alami yang baik bagi kesehatan. Minyak argan adalah minyak yang stabil karena mengandung sejumlah besar antioksidan alami, terutama tokoferol yang merupakan molekul dengan sifat antioksidan dan radikal bebas yang kuat [2]. Minyak argan mengandung senyawa fenolik yang tinggi dan merupakan penangkal radikal kuat dan dapat digunakan sebagai sumber potensial antioksidan alami untuk penggunaan medis dan komersial [3].

Untuk mencapai efek optimum antioksidan dari minyak argan, maka diperlukan suatu sistem penghantaran yang baik yaitu dalam bentuk sediaan mikroemulsi. Mikroemulsi merupakan suatu sistem penghantaran yang stabil secara termodinamika, transparan serta memiliki ukuran globul yang kecil, terdiri dari campuran minyak, air, surfaktan dan ko-surfaktan. Dimana mikroemulsi memiliki potensi besar dalam penghantaran zat 
aktif secara dermal bagi senyawa hidrofilik dan lipofilik dengan meningkatkan permeabilitas transdermal dalam penghantaran obat secara topikal serta memiliki beberapa kelebihan diantaranya yaitu dapat menjaga kestabilan obat yang labil, pelepasan obat terkontrol serta melarutkan obat yang bersifat hidrofobik maupun larut dalam minyak [4].

Salah satu metode yang paling umum digunakan untuk menguji aktivitas antioksidan adalah dengan menggunakan radikal bebas 1,1-diphenyl-2- picrylhydrazil (DPPH). Metode DPPH dapat memberikan hasil yang akurat, reliabel, cepat dan praktis sehingga sering digunakan. Pada penelitian ini minyak argan diformulasikan dalam bentuk sediaan mikroemulsi dan menguji aktivitas antioksidan menggunakan metode pemerangkapan radikal bebas 1,1-diphenyl-2-picryhydrazil (DPPH).

\section{Metode}

\subsection{Alat dan Bahan}

Alat yang digunakan yaitu alat-alat gelas, timbangan analitik, Spektrofotometer UVVIS, hot plate, magnetic stirrer, indikator $\mathrm{pH}$, sentrifugasi, viskometer brokfield. Bahan yang digunakan pada penelitian ini yaitu minyak argan (Argania Spinosa L), Tween 80, Alkohol, Isopropil Miristat, gliresin, dan aquades.

\subsection{Prosedur Kerja}

\subsubsection{Optimasi Basis Mikroemulsi}

Surfaktan dan ko-surfaktan dicampur (campuran 1), pada campuran 1 ditambahkan fase minyak (campuran 2). Selanjutnya distirer dengan menggunakan magnetic stirrer hingga homogen. Campuran 2 ditambahkan air sedikit demi sedikit dan distirer kembali menggunakan magnetic stirrer dengan kecepatan $200 \mathrm{rpm}$ selama 3 menit sampai terbentuk campuran yang homogen dan bening. Setelah diperoleh campuran yang homogen dilakukan ultrasonikasi selama 15 menit dan didiamkan. Pengamatan dilakukan selama 24 jam pada setiap basis formula melalui pengamatan tingkat kekeruhan dan dilanjutkan dengan uji sentrifugasi.

\subsubsection{Formulasi Mikroemulsi Minyak Argan}

Gliserin dan alkohol sebagai kosurfaktan dicampur dan diaduk hingga homogen (campuran 1). Fase minyak yaitu minyak argan dan IPM dicampur dan diaduk hingga homogen (campuran 2). Campuran 2 dimasukkan kedalam fase air yaitu tween dan diaduk hingga jernih lalu ditambahkan campuran 1 dan diaduk menggunakan magnetic stirrer hingga homogen dengan kecepatan $200 \mathrm{rpm}$ selama 3 menit. Setelah diperoleh campuran yang homogen dilakukan ultrasonikasi selama 15 menit dan didiamkan hingga 24 jam.

\subsubsection{Evaluasi Sediaan}

1. Pengamatan Organoleptis

Pemeriksaan organoleptis meliputi warna, bau, dan kejernihan.

2. Evaluasi Sentrifugasi

Uji stabilitas mekanik dilakukan dengan cara sentrifus dengan kecepatam $3750 \mathrm{rpm}$ selama 5 jam. Setelah disentrifugasi dilihat mikroemulsi tetap jernih, tidak terjadi pemisahan fase, atau terbentuk endapan.

\section{Evaluasi Freeze-thaw}

Evaluasi dilakukan dengan menempatkan sediaan pada suhu $4^{\circ} \mathrm{C}$ selama 24 jam kemudian dipindahkan dan ditempatkan pada ruangan bersuhu $40^{\circ} \mathrm{C}$ selama 24 jam, proses ini dihitung 1 siklus. Evaluasi ini berlangsung selama 7 siklus dengan mengamati perubahan $\mathrm{pH}$ dan viskositas serta tampilan sediaan.

\subsubsection{Uji Aktivitas Antioksidan}




\section{Pembuatan Larutan DPPH}

Larutan DPPH 0,5 mM sebagai larutan pereaksi, dibuat dengan cara menimbang 0,018 g serbuk DPPH dan dimasukkan ke dalam labu ukur $100 \mathrm{~mL}$ dan ditambahkan etanol hingga tanda batas, didapatkan konsentrai 0,5 mM yang dihitung terhadap BM DPPH sebesar 394,32 / mol.

2. Pengukuran Aktivitas Antioksidan Minyak Argan (Argania spinosa L.)

Dibuat larutan stok 1000 ppm dengan cara melarutkan 0,1 g minyak argan ke dalam 100 $\mathrm{mL}$ metanol. Dibuat larutan standar 5 ppm, 10 ppm, 20 ppm, 40 ppm dan 80 ppm dari larutan stok. Diambil $2 \mathrm{~mL}$ dari masing-masing larutan standard an ditambahkan larutan DPPH sebanyak $2 \mathrm{~mL}$ dan ditambahkan $1 \mathrm{~mL}$ metanol. Larutan divorteks dan diinkubasi selama 30 menit pada suhu $37^{\circ} \mathrm{C}$. Dibaca absorbansinya pada spektrofotometri UV-Vis pada panjang gelombang $519 \mathrm{~nm}$.

3. Pengukuran Aktivitas Antioksidan Kontrol Positif (Vitamin E)

Dibuat larutan stok 1000 ppm dengan cara melarutkan 0,1 g vitamin E ke dalam $100 \mathrm{~mL}$ metanol. Dibuat larutan standar 20 ppm, 40 ppm, 60 ppm, 80 ppm dan 100 ppm dari larutan stok. Diambil $2 \mathrm{~mL}$ dari masing-masing larutan standard dan ditambahkan larutan DPPH sebanyak $2 \mathrm{~mL}$ dan ditambahkan $1 \mathrm{~mL}$ metanol. Larutan divorteks dan diinkubasi selama 30 menit pada suhu $37^{\circ} \mathrm{C}$. Dibaca absorbansinya pada spektrofotometri UV-Vis pada panjang gelombang $519 \mathrm{~nm}$.

4. Uji Aktivitas Antioksidan Sediaan Mikroemulsi Minyak Argan (Argania spinosa L.) Masing-masing formula F1, F2 dan F3 dibuat larutan stok 1000 ppm dengan cara melarutkan 0,1 g sediaan mikroemulsi ke dalam $100 \mathrm{~mL}$ metanol. Dibuat larutan standar 20 ppm, 40 ppm, 60 ppm, 80 ppm dan 100 ppm dari larutan stok. Diambil 2 mL dari masing-masing larutan standard an ditambahkan larutan DPPH sebanyak $2 \mathrm{~mL}$ dan ditambahkan $1 \mathrm{~mL}$ metanol. Larutan divorteks dan diinkubasi selama 30 menit pada suhu $37^{\circ} \mathrm{C}$. Dibaca absorbansinya pada spektrofotometri UV-Vis pada panjang gelombang $519 \mathrm{~nm}$. Dihitung masing-masing persen pengikatan DPPH dengan minyak argan (Argania spinosa L.), DPPH dengan vitamin E dan DPPH dengan mikroemulsi minyak argan dengan menghitung persen inhibisi, dengan rumus:

$$
\% \text { Aktivitas antioksidan }=\frac{\text { Absorbansi blanko }- \text { absorbansi sampel }}{\text { Absorbansi blanko }} \times 100 \%
$$

Nilai $\mathrm{IC}_{50}$ (Inhibition Conceentration) adalah konsentrasi antioksidan $(\mu \mathrm{g} / \mathrm{mL})$ yang mampu memberikan persen perendaman radikal sebanyak $50 \%$ disbanding dengan kontrol melalui persamaan garis. Nilai $\mathrm{IC}_{50}$ diperoleh dari perpotongan garis antara $50 \%$ daya hambatan dengan sumbu konsentrasi, kemudian masukan persamaan $\mathrm{y}=\mathrm{a}+\mathrm{bx}$. Dimana $\mathrm{y}=50$ dan nilai $\times$ menunjukan $\mathrm{IC}_{50}$.

2.2.5 Analisis Data

Analisis data dilakukan menggunakan uji statistik yaitu one way anova, untuk melihat stabilitas fisik sediaan mikroemulsi minyak argan (Argania spinosa L), serta Uji T Test untuk melihat perubahan aktivitas antioksidan pada $t_{0}$ dan $t_{28}$.

\section{Hasil dan Pembahasan}

\subsection{Optimasi Basis Mikroemulsi}

Penelitian diawali dengan optimasi basis terlebih dahulu untuk menentukan perbandingan minyak, surfaktan dan kosurfaktan yang tepat agar terbentuk mikroemulsi yang stabil, jernih dan transparan. Konsentrasi surfaktan harus cukup tinggi agar dapat menghasilkan tegangan antar muka yang sangat rendah, dan membentuk film antar muka antara minyak dan air [5]. Pada formula digunakan 
surfaktan tween 80, memiliki nilai HLB 15 yang bersifat hidrofilik, dan sesuai dengan mikroemulsi tipe minyak dalam air (M/A) yang dibuat [6]. Selain itu, tween 80 adalah surfaktan golongan non ionik, yang memiliki sifat toksisitas rendah dan tidak mengiritasi kulit sehingga baik digunakan secara topical [7].

3.2 Hasil Evaluasi Organoleptik

Untuk mengurangi konsentrasi surfaktan diperlukan kosurfaktan. Kosurfaktan berperan menurunkan tegangan antar muka, meningkatkan fleksibilitas film yang dibentuk surfaktan. Kosurfaktan yang digunakan dalam formulasi yaitu gliserin dan alkohol. Gliserin memiliki sifat yang rentan terhadap oksidasi pada penyimpanan dan juga bisa digunakan sebagai peningkat penetrasi sediaan topikal [6]. Alkohol dan gliserin sebagai kosurfaktan bisa berpenetrasi pada lapisan surfaktan dan minyak sehingga dapat menurunkan tegangan antarmuka air-minyak hingga kenilai terendah sehingga akan menghasilkan mikroemulsi [8].

Pada optimasi basis, fase minyak yang digunakan yaitu isopropil miristat (IPM). IPM bersifat tahan terhadap oksidasi dan hidrolisis, selain itu juga IPM dapat meningkatkan penetrasi dan penghantaran transdermal sehingga dapat meningkatkan absorbsi obat ke dalam kulit [9]. Konsentrasi yang digunakan yaitu sebanyak 3\%. Pembuatan mikroemulsi dilakukan secara hati-hati dengan memperhatikan suhu, serta waktu dan kecepatan pengadukan. Suhu yang digunakan yaitu suhu ruang, untuk mencegah terjadinya penurunan tegangan antar muka. Proses pengadukan yang dilakukan tidak lama dan tidak terlalu cepat. Proses pengadukan dapat membentuk sediaan mikroemulsi dengan mendispersikan fase terdispersi karena adanya energi kinetik yang diberikan dapat menyebabkan fase terdispersi terpecah menjadi globul-globul kecil. Pengadukan yang terlalu lama akan membuat tetesan-tetesan dalam mikroemulsi berbenturan dan akan membentuk globul yang lebih besar, mikroemulsi yang dihasilkan akan menjadi tidak stabil dengan terbentuknya pemisahan fase. Sedangkan pengadukan yang telalu singkat akan menyebabkan pengumpalan bahan-bahan yang tidak homogen sehingga akan menghasilkan mikroemulsi menjadi keruh [10].

Tabel 1. Hasil optimasi basis mikroemulsi

\begin{tabular}{cccccccc}
\hline Bahan & \multicolumn{7}{c}{ Formula \% } \\
\cline { 2 - 9 } & F1 & F2 & F3 & F4 & F5 & F6 & F7 \\
\cline { 2 - 9 } IPM & $\mathbf{1 : 8}$ & $\mathbf{1 : 9}$ & $\mathbf{1 : 1 0}$ & $\mathbf{1 : 1 1}$ & $\mathbf{1 : 1 2}$ & $\mathbf{1 : 1 3}$ & $\mathbf{1 : 1 4}$ \\
\hline Tween 80 & 18 & 20 & 22 & 24 & 26 & 28 & 30 \\
\hline Gliserin & 1 & 1 & 2 & 3 & 1 & 2 & 3 \\
\hline Alkohol & 5 & 6 & 6 & 6 & 9 & 9 & 9 \\
\hline Aquadest & 100 & 100 & 100 & 100 & 100 & 100 & 100 \\
\hline $\begin{array}{c}\text { Evaluasi } \\
\text { Kejernihan }\end{array}$ & Keruh & Keruh & Keruh & Agak & Agak & Jernih & Jernih \\
\hline
\end{tabular}

Hasil optimasi basis pada tabel 1. menunjukan formula F1 sampai F3 meghasilkan sediaan yang keruh. Hal ini kemungkinan kurangnya jumlah surfaktan dan kosurfaktan yang diperlukan untuk membentuk lapisan film disekeliling globul sehingga mikroemulsi yang dihasilkan keruh. Formula F4 dan F5 memiliki tampilan fisik agak keruh. Pada formula F6 dan F7 yang memiliki tampilan jernih, tetapi terdapat busa pada permukaan sediaan formula F7 sehingga dipilih formula F6. Konsentrasi tween pada 
formula F6 yaitu 28\%, dimana konsentrasi tersebut tidak melebihi batas penerimaan kulit. Konsentrasi alkohol pada formula F6 yaitu sebesar 9\%. Penggunaan konsentrasi tersebut terbilang aman karena tidak akan mengiritasi kulit, alkohol pada sediaan topikal akan mengiritasi kulit jika penggunaan konsentrasi diatas 50\%[6].

Tabel 2. Hasil formulasi mikroemulsi

\begin{tabular}{cccc}
\hline Bahan & \multicolumn{3}{c}{ Formula \% } \\
\cline { 2 - 4 } & F1 & F2 & F4 \\
\hline Minyak Argan & 0.5 & 1 & 1.5 \\
\hline IPM & 3 & 3 & 3 \\
\hline Tween 80 & 28 & 28 & 28 \\
\hline Alkohol & 2 & 2 & 2 \\
\hline Gliserin & 9 & 9 & 9 \\
\hline Aqudest add & 100 & 100 & 100 \\
\hline Evaluasi kejernihan & Jernih & Jernih & Jernih \\
\hline
\end{tabular}

Formula F6 selanjutnya diuji sentrifugasi, dilakukan selama 5 jam dengan kecepatan $3750 \mathrm{rpm}$, tujuan dilakukan uji sentrifugasi adalah untuk mengetahui apakah terjadi pemisahan fasa dan untuk mengetahui kestabilan sediaan selama satu tahun apabila disimpan pada suhu kamar [11]. Tidak terdapat pemisahan pada formula F6, tidak ada pengendapan dan tetap jernih.

3.3 Formulasi Sediaan Mikroemulsi Minyak Argan (Argania spinosa L.)

Hasil optimasi basis F6 selanjutnya ditambahkan minyak argan (Argania spinosa L.) dengan 3 variasi konsentrasi yaitu F1 0,5\%, F2 1\%, dan F3 1,5\%. Penambahan minyak argan pada formula dengan cara mencampurkannya dengan fase minyak yaitu IPM. Pada penambahan minyak argan dalam formula tidak menyebabkan perubahan tampilan fisik sediaan, dimana sediaan tetap jernih dan transparan.

3.4 Evaluasi Stabilitas Sediaan Mikroemulsi Minyak Argan (Argania spinosa L.)

Stabilitas sediaan farmasi merupakan kemampuan suatu produk untuk bertahan dalam batas yang ditetapkan sepanjang periode penyimpanan dan penggunaan, dimana sifat dan karakteristik sediaan yang dimiliki masih sama dengan pada saat dibuat [13]. Uji stabilitas terdiri dari stabilitas fisik dan kimia. Pada penelitian dilakukan uji stabilitas fisik meliputi evaluasi organoleptis, $\mathrm{pH}$, viskositas, sentrifugasi dan freeze-thaw.

Tabel 3. Hasil evaluasi organoleptis

\begin{tabular}{ccccccc}
\hline Formula & \multicolumn{2}{c}{ Warna } & \multicolumn{2}{c}{ Bau } & \multicolumn{2}{c}{ Homogenitas } \\
\hline & $\mathbf{t}_{0}$ & $\mathbf{t}_{28}$ & $\mathbf{t}_{0}$ & $\mathbf{t}_{28}$ & $\mathbf{t}_{0}$ & $\mathbf{t}_{28}$ \\
\hline F1 & Kuning & Kuning & Khas tween & Khas tween & Homogen & Homogen \\
& Bening & Bening & & & & \\
\hline F2 & Kuning & Kuning & Khas tween & Khas tween & Homogen & Homogen \\
& Bening & Bening & & & & \\
\hline F3 & Kuning & Kuning & Khas tween & Khas tween & Homogen & Homogen \\
& Bening & Bening & & & & \\
\hline
\end{tabular}

Tabel 4. Hasil evaluasi $\mathrm{pH}$

\begin{tabular}{cccc}
\hline Waktu/T (Hari) & \multicolumn{3}{c}{ Ph } \\
\cline { 2 - 4 } & F1 0.5\% & F2 1\% & F3 1.5\% \\
\hline $\mathbf{0}$ & 7 & 7 & 7 \\
\hline $\mathbf{4}$ & 7 & 7 & 7 \\
\hline $\mathbf{8}$ & 7 & 7 & 7 \\
\hline
\end{tabular}




\begin{tabular}{llll}
\hline $\mathbf{1 2}$ & 7 & 7 & 7 \\
\hline $\mathbf{1 6}$ & 6 & 7 & 7 \\
\hline $\mathbf{2 0}$ & 6 & 7 & 6 \\
\hline $\mathbf{2 4}$ & 6 & 6 & 6 \\
\hline $\mathbf{2 8}$ & 6 & 6 & 6
\end{tabular}

Evaluasi organoleptik bertujuan untuk melihat perubahan tampilan fisik sediaan meliputi perubahan warna, bau dan homogenitas. Pada tabel 4. menunjukkan hasil evaluasi organoleptik formula F1, F2, dan F3 pada hari pertama dan hari ke-28, tidak mengalami perubahan warna, bau maupun homogenitas. Ketiga formula sediaan memiliki warna kuning jernih dan bauh khas tween, dimana warna dan bau tersebut dihasilkan dari surfaktan yang digunakan dengan konsentrasi lebih tinggi dari bahan lainnya, serta ketiga sediaan tampak homogen dan transparan sesuai dengan syarat dari mikroemulsi yang harus memiliki tampilan fisik yang jernih dan transparan.

Pada hasil evaluasi $\mathrm{pH}$ ketiga formula sediaan yang didapatkan yaitu 7 dan mengalami penurunan menjadi 6. Evaluasi $\mathrm{pH}$ bertujuan untuk mengetahui keamanan suatu sediaan, terutama sediaan topikal. Idealnya sediaan topikal mempunyai nilai $\mathrm{pH}$ yang sama dengan $\mathrm{pH}$ kulit agar tidak terjadi iritasi pada permukaan kulit, dimana $\mathrm{pH}$ kulit berkisar antara 4-8 [12]. Sehingga hasil evaluasi $\mathrm{pH}$ sesuai dengan yang diharapkan.

Tabel 5. Hasil evaluasi viskositas

\begin{tabular}{cccc}
\hline Waktu/T (Hari) & \multicolumn{3}{c}{ Viskositas } \\
\cline { 2 - 4 } & $\mathbf{F 1 ~ 0 . 5 \%}$ & F2 1\% & F3 1.5\% \\
\hline $\mathbf{0}$ & 320 & 212 & 212 \\
\hline $\mathbf{4}$ & 320 & 212 & 212 \\
\hline $\mathbf{8}$ & 340 & 200 & 208 \\
\hline $\mathbf{1 2}$ & 344 & 228 & 226 \\
\hline $\mathbf{1 6}$ & 344 & 244 & 240 \\
\hline $\mathbf{2 0}$ & 366 & 220 & 222 \\
\hline $\mathbf{2 4}$ & 346 & 212 & 216 \\
\hline $\mathbf{2 8}$ & 346 & 268 & 264 \\
\hline
\end{tabular}

Tujuan dari uji viskositas adalah untuk mengetahui konsistensi dari sediaan yang dibuat. Viskositas memiliki pengaruh pada penggunaan obat yang diaplikasikan secara topikal, makin rendah nilai viskositas suatu sediaan makin mudah digunakan dan sebaliknya makin tinggi nilai viskositas makan seiaan akan susah dioleskan pada kulit [14]. Mikroemulsi memiliki nilai viskositas kurang dari $200 \mathrm{cPs}$ [13]. Berdasarkan hasil yang didapatkan pada tabel , 5 viskositas ketiga formula memiliki nilai lebih dari 200 cPs. Hal tersebut kemungkinan karena adanya gliserin yang digunakan, dimana gliserin mampu mengikat air sehingga dapat meningkatkan ukuran unit molekul.

Uji sentrifugasi dilakukan selama 5 jam dengan kecepatan $3750 \mathrm{rpm}$, tujuan dilakukan uji sentrifugasi adalah untuk mengetahui apakah terjadi pemisahan fasa dan untuk mengetahui kestabilan sediaan selama satu tahun apabila disimpan pada suhu kamar [11]. Pada ketiga formula menunjukan sediaan tetap stabil, tidak terjadi pemisahan, tidak ada pengendapan dan tetap jernih.

Tabel 6. Hasil evaluasi pH pada freeze-thaw

\begin{tabular}{cccc}
\hline Waktu/T (Hari) & \multicolumn{3}{c}{ Ph } \\
\cline { 2 - 4 } & F1 0.5\% & F2 1\% & F3 1.5\% \\
\hline 0 & 7 & 7 & 7 \\
\hline
\end{tabular}




\begin{tabular}{cccc}
\hline $\mathbf{4}$ & 7 & 7 & 7 \\
\hline $\mathbf{8}$ & 7 & 6 & 6 \\
\hline $\mathbf{1 2}$ & 6 & 6 & 6 \\
\hline $\mathbf{1 6}$ & 6 & 6 & 6 \\
\hline $\mathbf{2 0}$ & 6 & 6 & 6 \\
\hline $\mathbf{2 4}$ & 6 & 6 & 6 \\
\hline $\mathbf{2 8}$ & 6 & 6 & 6 \\
\hline
\end{tabular}

Tabel 7. Hasil evaluasi viskositas pada suhu freeze-thaw

\begin{tabular}{cccc}
\hline Waktu/T (Hari) & \multicolumn{3}{c}{ Viskositas } \\
\cline { 2 - 4 } & F1 0.5\% & F2 1\% & F3 1.5\% \\
\hline 0 & 320 & 212 & 212 \\
4 & 320 & 212 & 212 \\
\hline 8 & 344 & 216 & 232 \\
\hline 12 & 344 & 216 & 236 \\
\hline 16 & 324 & 200 & 236 \\
\hline 20 & 320 & 200 & 212 \\
\hline 24 & 296 & 200 & 216 \\
\hline 28 & 288 & 184 & 200 \\
\hline
\end{tabular}

Berdasarkan hasil yang didapatkan pada tabel 6 dan 7, nilai $\mathrm{pH}$ dan viskositas ketiga formula pada suhu freeze-thaw tidak jauh berbeda dengan nilai $\mathrm{pH}$ dan viskositas pada suhu ruang. Pada ketiga formula juga tidak terjadi pemisahan yang memperlihatkan kestabilan dari sediaan yang tetap jernih dan transparan.

Tabel 8. Hasil evaluasi stabilitas sentrifugasi

\begin{tabular}{cccc}
\hline Waktu/T & \multicolumn{3}{c}{ Sentrifugasi } \\
\cline { 2 - 4 } (Hari) & F1 0.5\% & F2 1\% & F3 1.5\% \\
\hline $\mathbf{0 - 2 8}$ & Tidak Memisah & Tidak Memisah & Tidak Memisah \\
\hline
\end{tabular}

Minyak argan (Argania spinosa L.) dalam bentuk mikroemulsi sama halnya dengan stabilitas fisik dalam bentuk emulsi. Penelitian El-Abassi dkk [16], memformulasikan minyak argan (Argania spinosa L.) dalam bentuk sediaan emulsi, menghasilkan stabilitas fisik yang baik selama penyimpanan dan relative monodispesrsi hingga 120 hari penyimpanan. Mikroemulsi minyak argan (Argania spinosa L.) yang dihasilkan juga memiliki stabilitas fisik yang baik.

3.5 Aktivitas Antioksidan

Nilai abosrbansi yang dihasilkan, digunakan untuk menunjukan aktivitas antioksidan. Pengukuran blangko DPPH diukur pada panjang gelombang 500-530. Hasil absorbansi DPPH sebagai blangko sebesar pada panjang gelombang $519 \mathrm{~nm}$. Untuk minyak argan (Argania spinosa L), didapatkan hasil $\mathrm{IC}_{50}$ sebesar $39.50 \mu \mathrm{g} / \mathrm{mL}$.

Tabel 9. Hasil aktivitas antiokidan minyak argan (Argania spinosa L.) dan vit. E

\begin{tabular}{cc}
\hline Sampel & $\mathrm{IC}_{50}(\boldsymbol{\mu g} / \mathbf{m L})$ \\
\hline Minyak argan & 39.50 \\
\hline Vitamin E & 17.33 \\
\hline
\end{tabular}

Tabel 10. Hasil aktivitas antiokidan sediaan mikroemulsi minyak argan (Argania spinosa L.)

Sampel $\quad \mathrm{IC}_{50}(\mu \mathrm{g} / \mathrm{mL})$




\begin{tabular}{ccc}
\hline & Hari Pertama $\left.\mathbf{( t}_{\mathbf{0}}\right)$ & Hari Ke-28 $\left(\mathbf{t}_{\mathbf{2 8}}\right)$ \\
\hline F1 & 291.14 & 230.43 \\
\hline F2 & 89.02 & 129.01 \\
\hline F3 & 81.07 & 116.30 \\
\hline
\end{tabular}

Hasil penelitian Kamal dkk [3], minyak argan memiliki aktivitas antioksidan yang dinyatakan dengan trolox equivalents (TE) berkisar antara 3.46-4.43 mg TE/g. Hasil penukuran vitamin E, didapatkan hasil 17,33 $\mu \mathrm{g} / \mathrm{mL}$. Pada tabel 4.10 menunjukan hasil aktivitas antioksidan sediaan mikroemulsi ketiga formula pada $\mathrm{T}_{0}$ dan $\mathrm{T}_{28}$ mengalami perubahan. Nilai $\mathrm{IC}_{50}$ Formula F1 pada $\mathrm{T}_{0}$ sebesar $291.14 \mu \mathrm{g} / \mathrm{mL}$ dan $\mathrm{T}_{28}$ sebesar 230.43 $\mu \mathrm{g} / \mathrm{mL}$. Nilai $\mathrm{IC}_{50}$ Formula $\mathrm{F} 2$ pada $\mathrm{T}_{0}$ sebesar $89.02 \mu \mathrm{g} / \mathrm{mL}$ dan $\mathrm{T}_{28}$ sebesar 129.01 $\mu \mathrm{g} / \mathrm{mL}$. Nilai $\mathrm{IC}_{50}$ Formula F3 pada $\mathrm{T}_{0}$ sebesar $81.07 \mu \mathrm{g} / \mathrm{mL}$ dan $\mathrm{T}_{28}$ sebesar 116.30 $\mu \mathrm{g} / \mathrm{mL}$. Suatu senyawa dikatakan memiliki antioksidan sangat kuat jika nilai $\mathrm{IC}_{50}<50$, kuat 50-100, sedang 100 -150 dan lemah 151-200 [17]. Berdasarkan hasil yang didapatkan minyak argan memiliki aktivitas antioksidan yang sangat kuat. Formula F1 memiliki aktivitas antioksidan yang sangat lemah. Sedangkan formula F2 dan F3, memiliki aktivitas antioksidan kuat dan menjadi sedang setelah penyimpanan selama 28 hari.

3.6 Uji Statistik

Aktivitas antioksidan ketiga formula pada hari pertam $\left(t_{0}\right)$ dan hari ke-28 $\left(t_{28}\right)$ diuji menggunakan paired T-Test, untuk melihat perbedaan bermakna nilai aktivitas antioksidan ketiga sediaan. Diperoleh harga $p$ value $=0,896,(>0.05)$, hal tersebut menunjukkan tidak ada perbedaan hasil uji aktivitas antioksidan ketiga formula pada hari pertam $\left(\mathrm{t}_{0}\right)$ dan hari ke-28 $\left(\mathrm{t}_{28}\right)$.

4. Kesimpulan

Berdasarkan hasil penelitian yang telah dilakukan dapat diambil kesimpulan bahwa, sediaan mikroemulsi minyak argan (Argania spinosa L.) memiliki aktivitas antioksidan dan mengalami perubahan nilai aktivitas antioksidan setelah penyimpanan 28 hari dengan nilai $\mathrm{IC}_{50}$ F1 $291.14 \mu \mathrm{g} / \mathrm{mL}$ menjadi $230.43 \mu \mathrm{g} / \mathrm{mL}, \mathrm{F} 289.02 \mu \mathrm{g} / \mathrm{mL}$ menjadi $129.01 \mu \mathrm{g} / \mathrm{mL}, \mathrm{F} 381.07 \mu \mathrm{g} / \mathrm{mL}$ menjadi $116.30 \mu \mathrm{g} / \mathrm{mL}$. Hasil uji statistik T Test $\mathrm{p}$ value $=0,896,(>0.05)$, tidak ada perbedaan yang hasil uji aktivitas antioksidan ketiga formula pada hari pertam $\left(\mathrm{t}_{0}\right)$ dan hari ke-28 $\left(\mathrm{t}_{28}\right)$.

\section{Referensi}

[1] Yadav, A. Kumari, R., Yadav, A., Mishra, J. P., Srivatva, S. \& Prabha, S. (2016). Antioxidants and its functions in human body - A Review. Research in Environment and Life Sciences. Vol 9

[2] Guillaume, D. dan Charrour, Z. (2011). Argan Oil. Medicine Review. Vol 16

[3] Kamal, R., Kharbach, M., Imig, J. D., Eljmeli, M., Doukkali, Z., Mrabti, H. N., Elmsellem, H., Bouklouze, A., Cherrah, Y., Alaoui, K., (2017). Antioxidant activities, total polyphenolic compounds and HPLC/DAD/MS phenolic profile of argan oil derived from two different methods of extractions. Journal of Materials and Environmental Sciences. Vol 8

[4] Chansakaow, S. Sirisa-Ard, P. dan Khonkarn, R. (2017). Preparation, Characterization And Antioxidant Activity Of Xanthone-Loaded Making (Hodgsonia Heteroclita) Microemulsions. International Journal Of Pharmacy And Pharmaceutical Sciences. Vol 9 
[5] Kumar, K. S., Dhachinamoorthi, D., Saravanan, R., Gopal, U. K. dan Shanmugam, V. Microemulsions As Carrier For Novel Drug Delivery: A Review. International Journal of Pharmaceutical Sciences Review and Research. Vol 10

[6] Rowe, R.C., Paul J. Sheskey, dan Marian E Quinn. 2009. Handbook Of Pharmaceutical Excipients. Sixth Edition. Pharmaceutical Press: London

[7] Sulastri, E., Oktaviani, C. dan Yusriadi. 2015. Formulasi Mikroemulsi Ekstrak Bawang Hutan dan Uji Aktivitas Antioksidan. Jurnal Pharmascience. Vol 2

[8] Martin, A., James, S. dan Arthur, C. 1993. Farmasi Fisik: Dasar-dasar Farmasi Fisik dalam Ilmu Farmasetik. UI Press: Jakarta

[9] Pamudji, J. S., Darijanto, S. T. dan Rosa, S. 2012. Formulasi dan Evaluasi Mikroemulsi Minyak dalam Air Betametason 17-Valerat. Acta Pharmaceutica Indonesia. Vol 38

[10] Hasrawati, A., Hasyim, N. dan Irsyad, N. A. 2012. Pengembangan Formulasi Mikroemulsi Minyak Sereh (Cymbopogon nardus) Menggunakan Emulgator Surfaktan Nonionik. Jurnal Fitofarmaka Indonesia. Vol. 3 No.1

[11] Lachman, L. Lieberman, H. A. dan Kanig, J. L. 1976. The Theory and Practice of Industrial Pharmacy. Lea and Febiger. Philadelphia

[12] Vadas, E. B. 2000. Stability of Pharmaceutical Products, dalam Gennaro, A. R. Remington: The Sciences and Practice of Pharmacy, 20 th edition Jilid I. Philladelphia College of Pharmacy and Sciences

[13] Danimayostu, A. A., Shofiana, N. M. dan Permatasari, D. 2017. Pengaruh Penggunaan Pati Kentang (Solanum tuberosum) Termodifikasi AsetilasiOksidasi sebagai Gelling agent terhadap Stabilitas Gel Natrium Diklofenak. Pharmaceutical Journal Of Indonesia. Vol 3(1)

[14] Sinko, P. J. 2006. Martin's Physical Pharmacy and Pharmaceutical Sciens Fifth Edition. Lippicott Wiliams \& Wilkins. Philadelphia

[15] Fitriani, E. W., Imelda, E., Kornelis, C. dan Avanti, C. 2016. Karakterisasi dan Stabilitas Fisik Mikroemulsi Tipe A/M dengan Berbagai Fase Minyak. Pharm Sci Res. Vol 3

[16] El-Abbassi, A., Neves, M. A., Kobayashi, I., Hafidi, A. dan Nakajima, M., 2013. Preparation and characterization of highly stable monodisperse argan oil-in-water emulsions using microchannel emulsification. Europe Journal Lipid Science Technology. Vol 115

[17] Badarinath, A., Rao, K., Chetty, CS., Ramkanth, S., Rajan, T. dan Gnanaprakash, K. 2010. A Review on In-vitro Antioxidant Methods : Comparisons, Correlations, and Considerations. International Journal of PharmTech Research. 